Pediatr. Res. 15: 330-334 (1981)

cartilage

chondroitin sulfates

chondrocyte
I-cell disease

osiluim

\title{
Cartilage of I-Cell Disease
}

\author{
HIROSHI NOGAMI, ${ }^{1221}$ ATSUHIKO OOHIRA. FUMIKO SUZUKI, AND KATSUYA TSUDA
}

Departments of Orthopaedic Surgery and Pediatrics. Central Hospital, and Department of Embryology. Institute for Developmental Research, Kasugai, Aichi, Japan

\section{Summary}

Biochemical analysis and morphologic observation of the iliac crest cartilage from 8-year-old girl with I-cell disease were performed. Instead of hypertrophic change of chondrocytes in the zone of cartilage-bone junction, there were small atrophic cells having many inclusion bodies accumulated with lamellar materials. Another characteristic finding in this zone was numerous cellular debris in the cartilage matrix. Significantly, a large amount of unsulfated chondroitin $(21 \%)$ occurred in the cartilage with I-cell disease, and compensatory decrease of chondroitin 4-sulfate (14\%) was observed. The percentage of chondroitin and chondroitin 4-
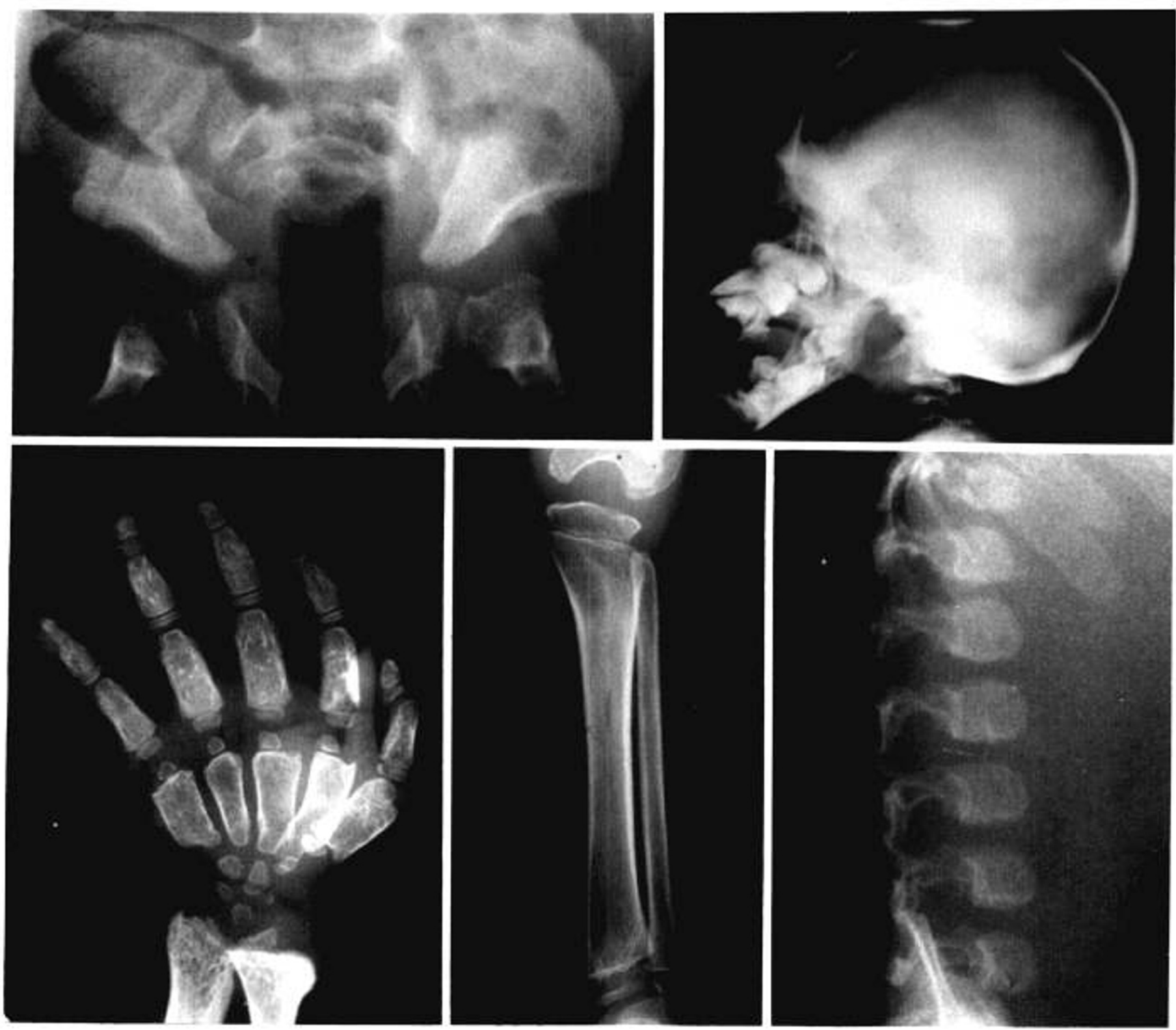

Fig. 1. Roentgenograms of 8-year-old girl with I-cell disease showing characteristic features of the affection. 
sulfate on the control averaged 8.5 and $43 \%$, respectively. The sedimentation profile of the proteoglycans closely resembled that of the normal cartilage.

\section{Speculation}

Occurrence of unsulfated chondroitin in cartilage matrix may reflect abnormality in the process of posttranslational assembly and modification of glycosaminoglycans in I-cell disease. Increase of cellular debris as well as appearance of atrophic chondrocytes in the zone of cartilage-bone junction may have relation with defective growth of the skeleton.

I-cell disease or mucolipidosis II is a disorder characterized by severe psychomotor retardation, skeletal dysplasia, and mucopolysaccharidosis-like features with an absence of excessive excretion of glycosaminoglycans in the urine $(4,8,9,19)$. Although recent findings in the research of pathogenesis of I-cell disease show considerable evidences that the defect in the disorder involves processing of lysosomal hydrolases $(1,6,10,18)$, biochemical analysis of matrix macromolecules of dysplastic skeletal tissue, which is one of the diagnostic criteria, has not been performed to date.

Glycosaminoglycans are major constituents of extracellular matrix of cartilage, and most of their integral parts are synthesized by the enzyme complex associated with the intracellular smooth membrane, the Golgi apparatus (5). Inasmuch as chondrocytes with I-cell disease have a disordered intracellular membranous system. one can postulate that the structure and content of glycosaminoglycans of I-cell disease may differ from those of the normal

In the present paper, we report the results of biochemical analysis of glycosaminoglycans and morphologic observation of ultrastructure of the iliac crest cartilage from 8-year-old girl with I-cell disease.

\section{MATERIALS AND METHODS}

We reported three cases of I-cell disease in 1975 and the last surviving patient (female), referred to as case 3 in the previous communication (19), died of pneumonia at the age of 8 years, 18 days. An examination of the autopsied iliac crest cartilage was performed. She has been unable to stand or talk since her birth. Roentgenographic findings at 8 years old are shown in Figure 1.

\section{MORPHOLOGICAL EXAMINATION}

Excised iliac cartilage was placed in $3 \%$ glutaraldehyde buffered to $\mathrm{pH} 7.4$ with $0.1 \mathrm{M}$ sodium cacodylate at $4^{\circ} \mathrm{C}$ for $2 \mathrm{hr}$. Postfixation was carried out in cacodylate-buffered $2 \%$ osmium tetroxide at $4^{\circ} \mathrm{C}$ for $3 \mathrm{hr}$. Some specimens were fixed in a solution of two parts of cacodylate-buffered 3\% glutaraldehyde and one part of ruthenium red (TAAB Laboratories) at $4^{\circ} \mathrm{C}$ for $2 \mathrm{hr}$ and postfixed in equal parts of $2 \%$ osmium tetroxide in cacodylate buffer and ruthenium red for $3 \mathrm{hr}(7)$. The samples were dehydrated in a series of solutions of ethanol and acetone, and embedded in Epon 812. Preliminary sections were cut at $0.5 \mu \mathrm{m}$ and stained with toluidine blue for the light microscopic observation. Thin sections were stained with uranyl acetate and lead citrate. Sections from samples stained with ruthenium red were stained with uranyl acetate. Observations were carried out under a JEOL JEM-100B electron microscope.

\section{BIOCHEMICAL ANALYSIS}

Preparation of glycosaminoglycans was performed by the method described in a previous paper (13). In brief, sliced, excised iliac crest cartilage was subjected to a sequential treatment of ice-

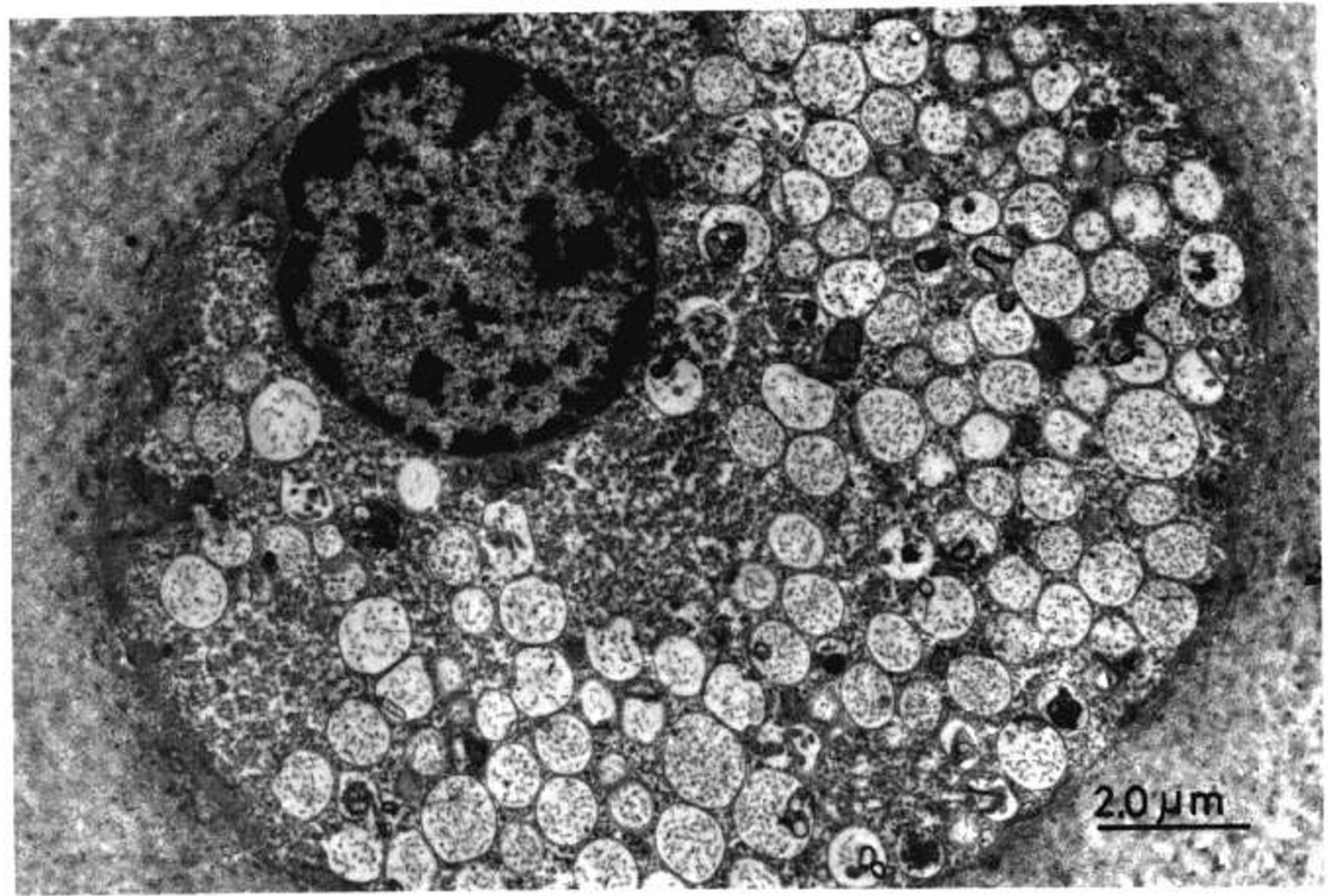

Fig. 2. Chondrocyte of I-cell disease is large in size, smooth in periphery, and filled with numerous cytoplasmic vacuoles bounded by the limiting membrane. Uranyl acetate and lead citrate stain. Original magnification: $\times 5000$. 


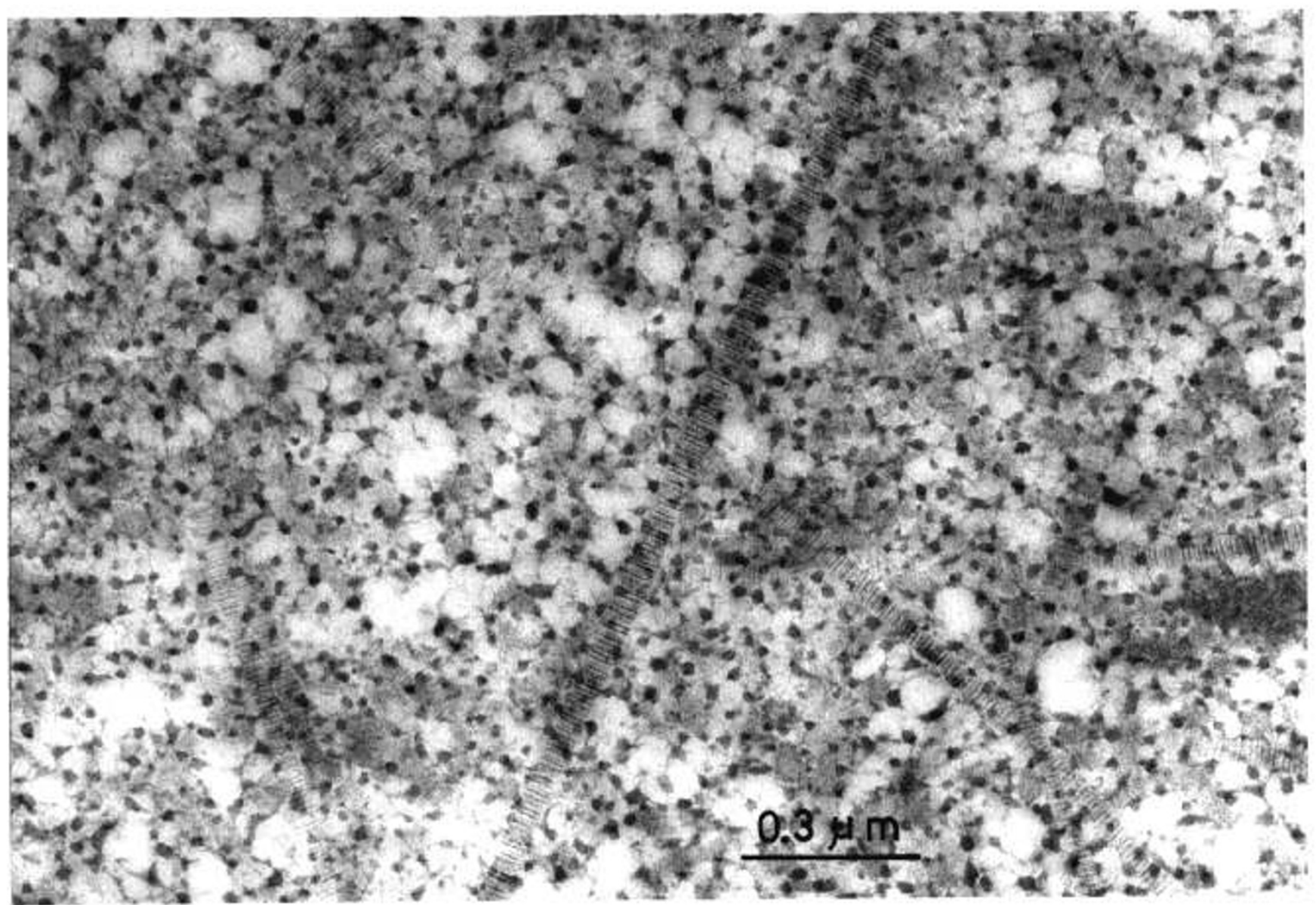

Fig. 3. Electron micrograph of cartilage matrix of I-cell disease, showing proteoglycan granules and collagen fibrils. Ruthenium red and uranyl acetate stain. Original magnification: $\times 40,000$

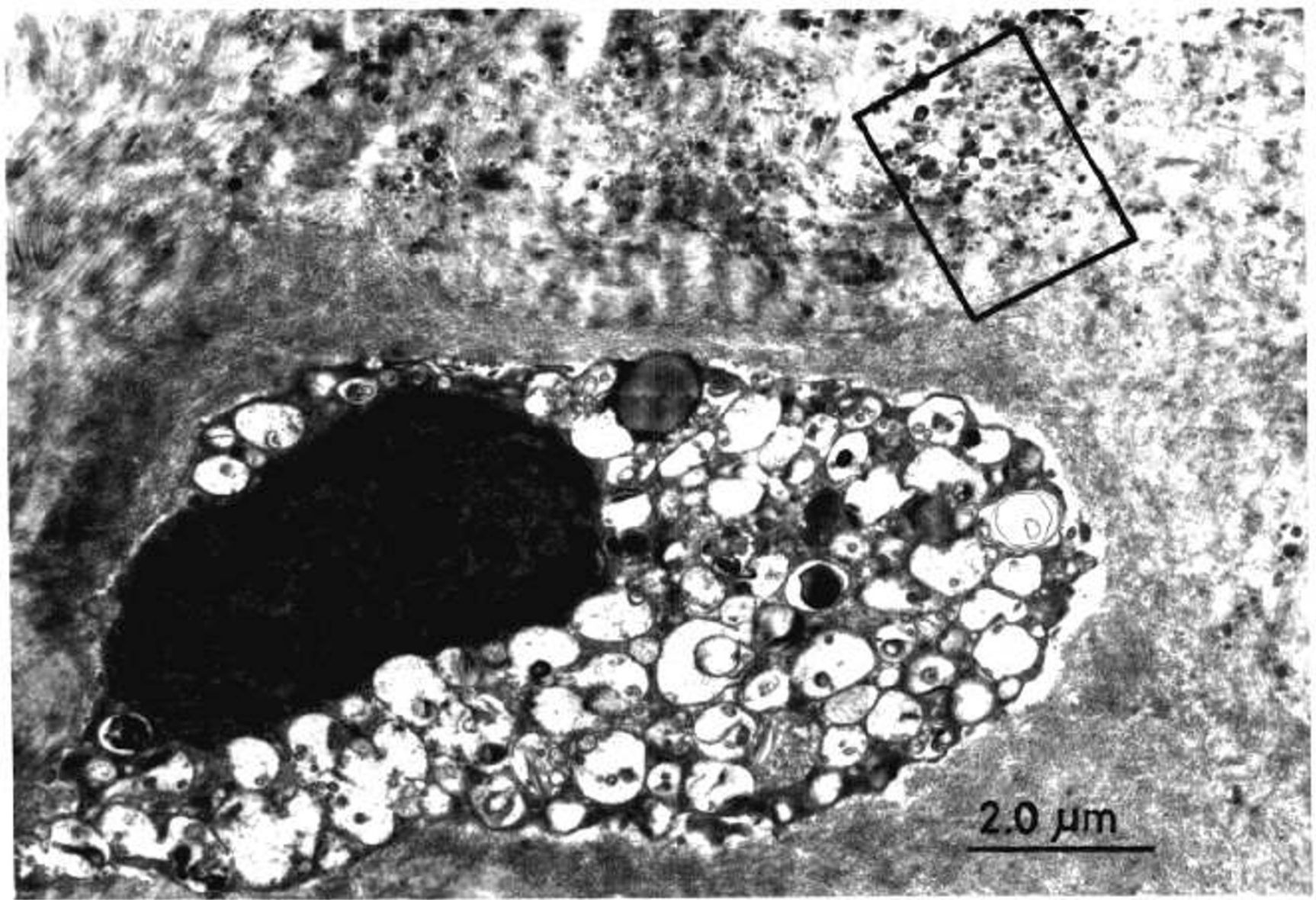

Fig. 4. I-cell disease chondrocyte in the zone of cartilage-bone junction is small in size and has increased lamellar figure materials in cytoplasmic vacuoles. Uranyl acetate and lead citrate stain. Original magnification: $\times 5700$. 


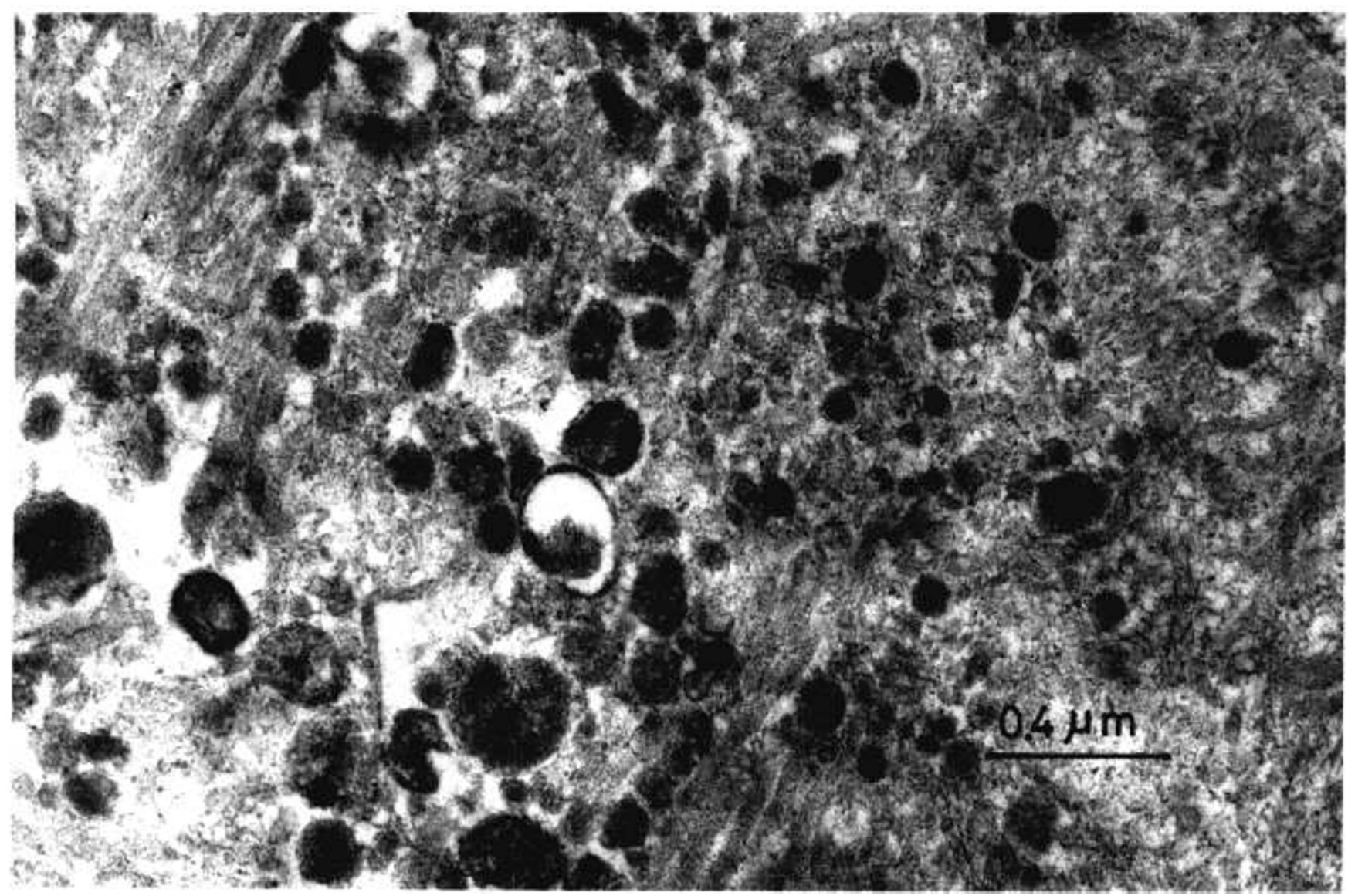

Fig. 5. Electron micrograph of boxed-in area of Figure 4, showing cellular debris in cartilage matrix. Uranyl acetate and lead citrate stain. Original magnification: $\times 30,000$.

cold acetone, pronase, $0.3 \mathrm{~N} \mathrm{NaOH}, 5 \%$ trichoroacetic acid, and $75 \%$ ethanol- $1 \%$ potassium acetate. The crude glycosaminoglycans thus prepared were digested with chondroitinase-ABC and assayed for the unsaturated disaccharide products to estimate the relative amounts of isomeric chondroitin sulfates (16).

\section{RESULTS}

Chondrocytes of the present case had numerous cytoplasmic inclusion bodies (Fig. 2) as in other cases with I-cell disease (19). Number, size, and area of ruthenium red-staining granules in the extracellular matrix were relatively small compared with other heritable disorders of connective tissue (11). Collagen fibrils were also relatively small in width (Fig. 3 ). In the present case, we could examine chondrocytes in the zone of cartilage-bone junction for the first time and found peculiar chondrocytes in this zone. Instead of hypertrophic change in chondrocytes as usually observed in this zone, there were many small atrophic cells with degenerative change. Inclusion bodies of these cells morphologically showed pleomorphic features and, especially, accumulation of lamellar or myelin figure materials increased in number (Fig. 4). Another characteristic finding in the zone of cartilage-bone junction was numerous cellular debris in the cartilage matrix. Most of these cellular debris had organelle-like structure bounded by a unit membrane (Fig. 5).

The glycosaminoglycan content in the affected cartilage tended to be slightly smaller than in the normal cartilage (Table 1). Different glycosaminoglycan levels between controls might indicate age-related change (3). The glycosaminoglycan preparation from the affected cartilage proved to consist mainly of chondroitin sulfates because most of the glycosaminoglycans were degrated by treatment with only chondroitinase-AC. The relative amounts of isomeric chondroitin sulfates are shown in Table 2 . Chondroitin 4-sulfate accounted for $50 \%$ of total chondroitin sulfates in the normal cartilage from a 2-year-old girl. The contents of unsulfated
Table 1. Glycosaminoglycan contents in iliac crest cartilage

\begin{tabular}{llccc}
\hline \multicolumn{1}{c}{ Age } & Sex & $\begin{array}{c}\text { Acetone- } \\
\text { dried tissue } \\
(\mathrm{mg})\end{array}$ & $\begin{array}{c}\text { Glycosami- } \\
\text { noglycans } \\
(\mu \mathrm{g} / \mathrm{mg})\end{array}$ \\
\hline I-cell disease & $8 \mathrm{yr}$ & $\mathrm{F}$ & 112.0 & 51.9 \\
Control-1 $^{1}$ & $2 \mathrm{yr}, 5 \mathrm{mos}$. & $\mathrm{F}$ & 45.8 & 119.0 \\
Control-2 $^{2}$ & $13 \mathrm{yr}$ & $\mathrm{F}$ & 84.0 & 54.6 \\
\hline
\end{tabular}

${ }^{1}$ Patient with spina bifida.

${ }^{2}$ Patient with scoliosis.

Table 2. Chondroitinase digestion products of glycosaminoglycans (\%) from iliac crest cartilage

\begin{tabular}{lccc}
\hline & I-cell disease & Control-1 & Control-2 \\
\hline Chondroitin & 21 & 10 & 7 \\
Chondroitin 4-sulfate & 14 & 50 & 36 \\
Chondroitin 6-sulfate & 65 & 40 & 57 \\
\hline
\end{tabular}

chondroitin and chondroitin 4-sulfate in the sample of a 13-yearold girl were smaller than those in the sample of a 2-year-old girl. This finding is consistent with the results that the relative amounts of unsulfated chondroitin and chondroitin 4-sulfate in human cartilage decrease with age and the content of chondroitin 6sulfate increases compensatorily (3). It is noteworthy that significantly large amount of unsulfated chondroitin occurs in the cartilage with I-cell disease (Table 2). Compensatory decrease in the amount of chondroitin 4-sulfate was also observed, whereas the content of chondroitin 6-sulfate was slightly more than those in the normal cartilage.

Proteoglycans, namely protein-bound form of glycosaminoglycans, were extracted from the cartilage with I-cell disease with 4 
M guanidine $\mathrm{HCl}$ containing protease inhibitors (12) and analyzed with centrifugation in a sucrose density gradient as described previously (14). The sedimentation profile of the proteoglycans was closely similar to those of the normal cartilage; two peaks of a major, heavy component and a minor, light component (data not shown). This finding indicates that, like the normal cartilage, the cartilage with I-cell disease can synthesize chondroitin sulfates in the protein-bound form.

\section{DISCUSSION}

Increased cellular debris in the matrix in consequence of excessive degeneration of chondrocytes in the zone of cartilage-bone junction may alter the site of initial nucleation and produce defective calcification or ossification leading to growth disturbance of the skeleton with I-cell disease. It is difficult to distinguish Icell disease from mucopolysaccharidoses only from the basis of morphologic features of chondrocytes, except relative increase of lamellar or ring-like materials in the cytoplasmic inclusion bodies. Increase of such lamellar materials in cells in the cartilage-bone junction may indicate increase of lipid storage (20).

In the cartilage of the present case, the relative amounts of isomeric chondroitin sulfates in the glycosaminoglycan side chains differ remarkably from the normal cartilage, although glycosaminoglycans are similar to normal ones in the protein bound form. Increased amount of unsulfated chondroitin and compensatorily decreased amount of chondroitin 4-sulfate are obvious in the cartilage with I-cell disease. There is no report on occurrence of unsulfated chondroitin in human cartilage to date, but cartilages containing significant amount of unsulfated chondroitin have been reported in some animals either with heritable or with experimentally produced skeletal dysplasia $(2,15,17)$. Therefore, one may consider that occurrence of unsulfated chondroitin is one of the causes of defective skeletal growth in the patient with I-cell disease. The exact mechanism operative in producing unsulfated chondroitin remains unknown. However, its occurrence in the cartilage may be interpreted by the following hypothesis; the primary defect or gene defect in glycosylation, secretion, endocytosis, and function of lysosomal hydrolases leads to abnormal concentration of intracellular lysosomal hydrolases resulting in a secondary biochemical phenomena such as abnormal sulfation of matrix glycosaminoglycans. Kimata et al. (5) demonstrated that an enzyme for 4-sulfation in cartilage was inactivated more easily by some treatments than an enzyme for 6 -sulfation. These enzymes are known to be associated with intracellular membrane of chondrocytes. The intracellular membranous disorder characteristic in I-cell disease may result in inactivation of 4-sulfotransferase of the chondrocytes. Alternatively, it may also be interpreted by activation of an enzyme which liberates sulfate from chondroitin 4- sulfate chains, but the occurrence of a 4-sulfatase has not been reported in cartilaginous tissue.

\section{REFERENCES AND NOTES}

1. Hasilik, A., Rome, L. H., and Neufeld, E. F.: Processing of lysosomal enzymes in human skin fibroblasts. Fed. Proc., 38: 467 (1979).

2. Hjelle, J. T., and Gibson, K. D.: Changes in collagen ultrastructure, macroscopic properties and chemical composition of chick embryo cartilage induced by administration of a $\beta$-D-xyloside. J. Embryol. Exp. Morphol., 53: 179 (1979).

3. Iwata, H.: The determination and the fine structures of chondroitin sulfate isomers of human cartilage and pathological tissues. J. Jap. Orthop. Assoc.. 43: 455 (1969)

4. Kelly, T.: The mucopolysaccharidoses and mucolipidoses. Clin. Orthop.. 114: 116 (1976).

5. Kimata, K., Okayama, M., Oohira, A., and Suzuki, S.: Cytodifferentiation and proteoglycan biosynthesis. Mol. Cell. Biochem., I: 211 (1973).

6. Kress, B. C.. Freeze, H. H., Herd, J. K., Alhadeff, J. A., and Miller, A. L. Purification and characterization of 1 -cell disease $\alpha$-L-fucosidase. J. Biol. Chem. 255: 955 (1980).

7. Laros, G. S., and Cooper, R. R.: Electron microscopic visualization of proteinpolysaccharides. Clin. Orthop., 84: 179 (1972).

8. Leroy, J. G., and DeMars, R. I.: Mutant enzymatic and cytological phenotypes in cultured human fibroblasts. Science (Wash. D. C.), 157: 804 (1967).

9. Martin. J. J., Leroy, J. G.. Farriaux. J. P.. Fontaine. G.. Desnick. R. J., and Cabello, A.: I-cell disease (Mucolipidosis II): a report on its pathology. Acta Neuropathol., 33: 285 (1975).

10. Miller, A. L., Levitt, P., Ingraham, H., Converse, J., and Lewis, L.: Properties of acid $\beta$-D-galactosidase isolated from I-cell disease brain and spleen. J. Neurochem., 32: 1479 (1979).

11. Nogami, H., Oohira, A., Ozeki, K., Oki, T., Ogino, T., and Murachi, S.: Ultrastructure of cartilage in heritable disorders of connective tissue. Clin. Orthop., 143: 251 (1979).

12. Oegema, T. R. Jr., Hascall, V. C., and Dziewiatkowski, D. D.: Isolation and characterization of proteoglycans from the Swarm rat chondrosarcoma. J. Biol. Chem., 250: 6151 (1975).

13. Oohira. A., Tamaki, K.. Terashima, Y., Chiba, A., and Nogami. H.: Glycosaminoglycans in congenital pseudarthrosis. Calcif. Tissue Res., 23: 271 (1977).

14. Oohira, A., Tamaki, K., Ozeki, K., Takamatsu, K., and Nogami, H.: Human cartilage proteoglycans isolated from normally ossifying and congenitally malformed leg bones. Calcif. Tissue Int.. 30: 183 (1980).

15. Orkin. R. W., Pratt, R. M., and Martin. G. R.: Undersulfated chondroitin sulfate in the cartilage matrix of brachymorphic mice. Dev. Biol., 50: 82 (1976).

16. Saito, H., Yamagata. T., and Suzuki, S.: Enzymatic methods for the determination of small quantities of isomeric chondroitin sulfates. J. Biol. Chem., 243: 1536 (1968).

17. Seegmiller, R. E., and Runner, M. N.: Normal incorporation rates for precursors of collagen and mucopolysaccharide during expression of micromelia induced by 6-aminonicotinamide. J. Embryol. Exp. Morphol., 31: 305 (1974).

18. Sly. W. S., Gonzalez-Noriega, A.. Natowicz. M., Fischer. H. D., and Chambers. j. P.: Role of the phosphomannosyl recognition marker in the uptake and transport of lysosomal enzymes. Fed. Proc., 38: 467 (1979).

19. Terashima. Y.. Tsuda, K., Isomura. S., Sugiura. Y.. and Nogami, H.: I-cell disease. Report of three cases. Am. J. Dis. Child.. 129: 1083 (1975).

20. Terry. R. D.: Some morphological aspects of the lipidosis. In: J. Bernsohn, H. J. Grossman: Lipid storage disease. p. 3 (Academic Press, Inc., New York. 1971). 21. Consent to materials was obtained by the authors.

22. Requests for reprints should be addressed to: Hiroshi Nogami. M.D.. Department of Orthopaedic Surgery, Central Hospital, 713-8 Kamiya-Cho. Kasugai, Aichi 480-03, Japan.

23. Received for publication April 30, 1980

24. Accepted for publication August 19, 1980. 